\title{
Non-verbal communication of compassion: measuring psychophysiologic effects
}

Kathi J Kemper ${ }^{1 *}$ and Hossam A Shaltout ${ }^{2}$

\begin{abstract}
Background: Calm, compassionate clinicians comfort others. To evaluate the direct psychophysiologic benefits of non-verbal communication of compassion (NVCC), it is important to minimize the effect of subjects' expectation. This preliminary study was designed to a) test the feasibility of two strategies for maintaining subject blinding to non-verbal communication of compassion (NVCC), and b) determine whether blinded subjects would experience psychophysiologic effects from NVCC.

Methods: Subjects were healthy volunteers who were told the study was evaluating the effect of time and touch on the autonomic nervous system. The practitioner had more than 10 years' experience with loving-kindness meditation (LKM), a form of NVCC. Subjects completed 10-point visual analog scales (VAS) for stress, relaxation, and peacefulness before and after LKM. To assess physiologic effects, practitioners and subjects wore cardiorespiratory monitors to assess respiratory rate (RR), heart rate (HR) and heart rate variability (HRV) throughout the 4 10-minute study periods: Baseline (both practitioner and subjects read neutral material); non-tactile-LKM (subjects read while the practitioner practiced LKM while pretending to read); tactile-LKM (subjects rested while the practitioner practiced LKM while lightly touching the subject on arms, shoulders, hands, feet, and legs); Post-Intervention Rest (subjects rested; the practitioner read). To assess blinding, subjects were asked after the interventions what the practitioner was doing during each period (reading, touch, or something else).
\end{abstract}

Results: Subjects' mean age was 43.6 years; all were women. Blinding was maintained and the practitioner was able to maintain meditation for both tactile and non-tactile LKM interventions as reflected in significantly reduced RR. Despite blinding, subjects' VAS scores improved from baseline to post-intervention for stress (5.5 vs. 2.2), relaxation (3.8 vs. 8.8) and peacefulness (3.8 vs. 9.0, $\mathrm{P}<0.05$ for all comparisons). Subjects also had significant reductions in $\mathrm{RR}(\mathrm{P}<0.0001)$ and improved HRV $(P<0.05)$ with both tactile and non-tactile LKM.

Conclusion: It is possible to test the effects of LKM with tactile and non-tactile blinding strategies; even with blinding in this small preliminary study, subjects reported significant improvements in well-being which were reflected in objective physiologic measures of autonomic activity. Extending compassion is not only good care; it may also be good medicine.

Trial registration number: US National ClinicalTrials.gov registration number, NCT01428674

\section{Background}

Compassionate communication is the cornerstone of clinical care. Although most research has focused on outcomes of verbal communication, there is little research on non-verbal communication, which experts estimate is the predominant form of communication

\footnotetext{
* Correspondence: kkemper@wakehealth.edu

${ }^{1}$ Social Science and Health Policy, Pediatrics, Center for Integrative Medicine, and Hypertension and Vascular Research Center; Wake Forest University

School of Medicine; Winston-Salem, NC, USA

Full list of author information is available at the end of the article
}

[1-4]. Positive non-verbal communication (NVC) can have powerful clinical benefits, but the precise mechanisms by which NVC of compassion (NVCC) benefits patients have not been fully explored [5]. Better understanding of the psychophysiologic mechanisms by which clinicians' NVCC (both non-verbal/non-tactile, and nonverbal/tactile communication) benefits patients could lead to innovations in educational strategies to maximize these benefits for a variety of clinicians, including psychotherapists, physicians, massage therapists, nurses, acupuncturists, and others who interact directly with

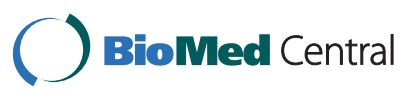


patients. It may also lay evidence-based groundwork to develop brief training interventions for parents or other caregivers to learn to effectively extend compassion and reduce stress in hospitalized or palliative care patients.

Studies in this area are challenging because subjects' expectations can strongly influence their response to an intervention [6-10]. That is, the expectation that one will receive benefit from a clinician may influence the impact of the clinician's actions or words [11-13]. When evaluating the effects of non-verbal communication of compassion (NVCC), minimizing subjects' expectations is critical for understanding its true effects. Although it is optimal for subjects to be blind to the NVCC, published protocols establishing effective blinding strategies are scarce; it would be useful to test two distinct strategies that might be employed under different experimental and clinical conditions. A non-tactile strategy would be relevant for studies of psychotherapists or social workers, while a tactile strategy would be relevant for studies of massage therapists and other body workers, acupuncturists, and other therapies or diagnostic maneuvers involving tactile contact.

We wished to test a form of NVCC associated with a calm face and lower respiratory rate. One type of mental activity that generally produces these effects in the practitioner is meditation [14-25]. Among the many types of meditation, loving-kindness-focused meditation (LKM) is attractive because the desire for increased well-being and decreased suffering is an explicit part of health care, regardless of the modality. In LKM, the practitioner focuses on the intention that another person experiences safety, health, peace, happiness, and freedom from suffering [26-28]. Although LKM has distinct physiologic effects on the practitioner [26,28-32], we are unaware studies evaluating the effect of one person practicing LKM on another person in the same room who is not meditating and blind to the practitioner's activity.

Therefore, to lay the groundwork for definitive clinical trials, we performed a preliminary study to answer questions about the feasibility of evaluating the psychophysiologic impact of NVCC on subjects blind to the intervention. Specifically, we wished to know:

Were two different strategies for blinding subjects to LKM intervention feasible? That is, would subjects remain blind and would the LKM provider be able to maintain LKM under these experimental conditions (non-tactile and tactile strategies)?

Would blind exposure to LKM be associated with any measurable changes subjects' psycho-emotional state and/or autonomic nervous system (ANS) activity?

The primary purpose of this study was to determine the feasibility of two different strategies for NVCC of compassion using LKM meditation in subjects blind to the study interventions. Because it was a preliminary feasibility study, we did not expect to find statistically significant differences, but we wished to observe changes in relaxation, peacefulness, stress, respiratory rate (RR), and vagal tone, reflected in increased heart rate variability (HRV), particularly High Frequency (HF) power in the power spectral analysis of HRV in order to calculate sample sizes for definitive studies.

\section{Methods \\ Subjects}

To address these questions, we recruited a convenience sample of adult volunteers at Wake Forest Baptist Health's Center for Integrative Medicine over 2 months prior to a grant deadline to obtain feasibility data for the proposal. Subjects were eligible if they were healthy and not taking medication for asthma, hypertension, or diabetes, or prophylactic medications, such as beta blockers for migraine headaches. Subjects were told the project was evaluating the effect of time, touch, and attention on autonomic nervous system (ANS) function, and were asked to remain quiet throughout the study period to avoid affecting ANS activity. Electronic devices such as cellular telephones and pagers were turned off during the study period to avoid disruptions. For this study, subjects served as their own control with baseline and follow-up periods compared with two NVCC periods.

\section{Practitioner}

Because previous studies have found differences between novice and experienced practitioners [32,33], we selected a practitioner with over 40 years of meditation experience. This senior staff member had engaged in LKM meditation daily for more than 5 years. Like the subjects, she was also a healthy female who was not taking beta blocking medications or any other medications affecting respiratory or heart rate.

\section{Procedure}

After informed consent, subjects completed brief questionnaires on demographics and 10 point self-report visual analog scales (VAS) for stress, relaxation, and peacefulness. After the interventions and the post-intervention rest period, subjects completed the same VAS.

After completing the baseline VAS, the subject and practitioner put on BioPac ${ }^{\circledR}$ Bioharness belts to collect continuous autonomic data for the 40 minute study. The Bioharness is an FDA-approved continuous ambulatory monitoring system which collects data on pulmonary, cardiac, and skin temperature measures with a sample rate set at $250 \mathrm{~Hz}$. It measures rib cage excursions for respiratory rate (RR) and an ECG to measure interbeat intervals to calculate heart rate variability (HRV); a built in thermometer measures skin 
temperature on the chest. The lightweight device is worn under normal clothing around the chest. It is machine washable, comfortable, and includes patented software which decrypts and processes the recorded data, and allows transformations of the data for export into statistical software.

Each subject underwent a standard study sequence consisting of four consecutive periods of 10 minutes each at one study visit: Baseline; Non-tactile LKM; Tactile-LKM; and Rest. (see Figure 1) If the purpose of the study had been to compare the effects of the two strategies, a random order separated by a rest period would be preferable, but for the purposes of this preliminary project (establishing feasibility), a standard sequence was used to minimize confusion among participants and staff.

During the Baseline control period, subject and practitioner sat in the same room approximately 8 feet apart and read quietly from an emotionally neutral textbook (MindSight by Daniel Siegel). During non-tactile NVCC, subjects continued to read; the practitioner practiced LKM while pretending to read (eyes open and turning pages as the subject turned pages). The practitioner focused on one phrase each breath for four breaths: 1) "may you be safe and secure", 2) "may you be healthy, comfortable and filled with vitality", 3) "may you be peaceful and happy", 4) "may you be free from suffering." The practitioner repeated the series of four breaths/lovingkindness thoughts throughout the $10 \mathrm{~min}$ ute intervention. During the tactile NVCC strategy, subjects were told we were testing the effect of light touch on the ANS; we asked the subject to sit quietly while the practitioner lightly touched her feet, legs, hands, arms, and shoulders. During tactile LKM, the practitioner again focused on the four lovingkindness phrases/ breaths with her eyes open, using the 4 phrase meditation as a timer so that each body part was touched for the time it took to complete 4 breaths before moving to a new area. Subjects sat in a straight back chair with arm rests, while the practitioner sat on a low rolling stool to facilitate moving to touch each side of the body. The practitioner was asked to keep her eyes open during both LKM interventions and avoid making eye contact with the subject. During the $4^{\text {th }}$ period, subjects rested quietly without reading and the practitioner remained in the room, quietly reading.

\section{Outcomes}

To assess blinding, at the end of the forty minute study period, the experimenter asked each subject open ended questions about what occurred during each study period. For example, what were you doing during the first reading period? What was the practitioner doing during the first reading period? What were you doing during the second reading period? What was the practitioner doing during the second reading period? What were you doing when the practitioner was touching you? What was the practitioner doing when she was touching you? What were you doing during the final rest period? What was the practitioner doing during the final rest period?

Respiratory rate (RR) was selected as the primary outcome for ANS function because it is easily observed and readily measured; it is sensitive to affective states and meditation [34,25,35-40]; and responds quickly to

\begin{tabular}{|c|c|c|c|c|c|c|}
\hline & $\begin{array}{l}\text { Pre- } \\
\text { VAS }\end{array}$ & $\begin{array}{l}\text { Baseline } \\
10 \mathrm{~min}\end{array}$ & $\begin{array}{l}\text { Non-tactile } \\
\text { LKM } \\
10 \mathrm{~min}\end{array}$ & $\begin{array}{l}\text { Tactile } \\
\text { LKM } \\
10 \mathrm{~min}\end{array}$ & $\begin{array}{l}\text { Rest } \\
10 \mathrm{~min}\end{array}$ & $\begin{array}{c}\text { Post- } \\
\text { intervention } \\
\text { VAS }\end{array}$ \\
\hline Subject & $\bar{X}$ & Read & Read & Rest & Rest & $X$ \\
\hline Practitioner & & Read & $\begin{array}{l}\text { Pretend to } \\
\text { read; } \\
\text { LKM }\end{array}$ & $\begin{array}{l}\text { Touch Subects' } \\
\text { hands, feet, } \\
\text { arms, legs; LKM }\end{array}$ & Read & \\
\hline Both & Bio & Ironon & itor: Respi & ory Rate, Heart $\mathrm{F}$ & e, Skin T & mperature \\
\hline
\end{tabular}

Figure 1 Study Visit. LKM- Lovingkindness meditation VAS- visual analog scales for stress, relaxation, peacefulness NVCC - Non-verbal communication of compassion. 
stimuli [41-44]. For analysis of RR, we downloaded the BioHarness data to an MS Excel database, analyzing median samples for 15 second epochs. Similar analyses were conducted for secondary outcomes of heart rate (HR) and peripheral skin temperature (Temp).

For heart rate variability (HRV) analyses, two parameters of interest were a) Total Power which reflects overall HRV, and activity in the high frequency (HF) power band of the power spectrum analysis, which reflects vagal tone in short-term recordings. BioPac ${ }^{\circledR}$ -acquired files were re-sampled at rate of $1 \mathrm{HZ}$, and the interbeat intervals (IBI) between successive RR-peaks files were analyzed using Nevrokard ${ }^{\circledR}$ - HRV software (Medistar, Ljubljana, Slovenia) using standard algorithms. Outliers were identified as all interbeat intervals (IBIs) demonstrating a 30\% difference from the mean of the previous four samples, and were removed from the data set. Power spectral densities for IBI were computed by Fast Fourier Transform (FFT), integrated over the standard frequency range (VLF; < 0.04 Hz), (LF; 0.04$0.15 \mathrm{~Hz}$ ) and (HF; 0.15-0.4 Hz), and a Hanning window was applied using standard methods [45-48].

As a secondary question, we explored practitionersubject correlation in RR.

\section{Analysis}

Analyses focused on descriptive statistics and impact on RR and VAS scales using SAS 9.2 (SAS Institute, Cary). Quantitative variables were summarized by means and standard deviations. The secondary outcome measures of subjects' HR, HRV, and skin temperature (Temp) were analyzed using these same methods. In addition to these models where each outcome is taken as a single value, we used a mixed models approach to allow for the repeated assessments of outcomes in each subject that occur during the study. In this model, participants are treated as random effects and overall dose and delivery estimates were calculated accounting for the repeated measurements. This approach allowed us to detect smaller differences than the ANCOVA models described above since they provide a more precise estimate of the outcome effects. All tests were two-sided with a type 1 error rate of $5 \%$.

This study was approved by the Institutional Review Board of Wake Forest School of Medicine.

\section{Results}

Because the study was designed primarily as a feasibility trial, we aimed for complete data collection on a convenience sample of 5 subjects; enrollment was closed when six subjects were recruited to provide an extra subject as back-up for missing data. All subjects were women; the mean age was $43.6 \pm 10.8$ years. None had any known cardiopulmonary conditions and none were taking beta-blocking medications.

\section{Feasibility}

Blinding was maintained, i.e., all subjects reported that the practitioner was reading during baseline, reading during the non-tactile LKM and touching during the tactile LKM. One subject reported that she thought the practitioner "might be meditating" (during non-tactile LKM) because "the room got really quiet", but when she looked, the practitioner was turning a page of the book, so "she must be really reading". The practitioner maintained a meditative state during both tactile and nontactile LKM interventions as reflected by her verbal report and in changes in RR. On average, the practitioner's RR fell from 15.9 breaths per minute (bpm) at baseline to $6.5 \mathrm{bpm}$ during non-tactile LKM and 8.2 bpm during tactile LKM, returning to $13.7 \mathrm{bpm}$ during the post-intervention rest $(\mathrm{P}<0.01$ for both LKMs vs. baseline and rest).

\section{Observed Psychophysiologic Effects}

As shown in Table 1, subjects reported decreases in stress and increases in relaxation and peacefulness after exposure to NVCC. For example, subjects' average relaxation increased from 3.8 at baseline to 8.8 on a 0 to 10 VAS after the NVCC interventions $(P<0.05$.) Subjects also had significant autonomic changes in the expected direction with NVCC. Subjects' average RR fell from baseline more than $4 \mathrm{bpm}$ during non-tactile-LKM $(\mathrm{P}<0.001)$ and more than $3 \mathrm{bpm}$ during tactile-LKM ( $\mathrm{P}$ $<0.001$ ), and remained an average of $1.4 \mathrm{bpm}$ below baseline values for the post-intervention rest period $(\mathrm{P}<$ 0.01). Heart rate fell for both tactile and non-tactile LKM interventions $(\mathrm{P}<0.05)$. Overall HRV, reflected in Total Power, increased significantly for both interventions compared to baseline $(\mathrm{P}<0.05)$. High Frequency (HF) power, reflecting primarily parasympathetic or vagal activity, increased from baseline for both tactile and non-tactile LKM, and declined to near baseline levels during the post-intervention rest periods $(\mathrm{P}<0.05$ for both). Peripheral skin temperature increased significantly over time $(\mathrm{P}<0.001)$; however, its steady increase throughout the study leads to concern that the device may simply take 40 minutes or more to reach an equilibration with skin temperature after being cleaned and then stored at room temperature.

In the analysis exploring the correlation between practitioner and subjects' respiratory rates, there was a significant correlation during non-tactile LKM $(\mathrm{r}=0.55, \mathrm{P}<$ 0.001 ). As the practitioner began to meditate, her RR fell rapidly, reaching the nadir of $<6 \mathrm{bpm}$ at 2.5 minutes, which was generally maintained until the end of non-tactile LKM. Subjects' RR also fell over the first 2.5 minutes, after which it stayed between 10 and $12 \mathrm{bpm}$ for the remainder of the period and remained lower than baseline during tactile LKM. (Figure 2) There were no significant 
Table 1 Changes from Baseline in Average Autonomic Nervous System Activity and Psycho-emotional State for Nontactile NVCC, Tactile NVCC, and Follow-up Rest in 6 healthy subjects

\begin{tabular}{|c|c|c|c|c|}
\hline Measure & $\begin{array}{l}\text { 1. Baseline } \\
\text { Mean }( \pm \text { SEM }) \\
10 \text { minutes }\end{array}$ & $\begin{array}{l}\text { 2. Change with Non-tactile NVCC } \\
\text { Mean }( \pm \text { SEM }) \\
10 \text { minutes }\end{array}$ & $\begin{array}{l}\text { 3. Change with Tactile NVCC } \\
\text { Mean }( \pm \text { SEM }) \\
10 \text { minutes }\end{array}$ & $\begin{array}{l}\text { 4. Rest } \\
\text { Mean }( \pm \text { SEM) } \\
10 \text { minutes }\end{array}$ \\
\hline \multicolumn{5}{|c|}{ Autonomic Data } \\
\hline $\begin{array}{c}\text { RR } \\
\text { (breaths per minute) }\end{array}$ & $15.33( \pm 1.67)$ & $-4.34( \pm 0.18)^{* * *}$ & $-3.55( \pm 0.11)^{* * *}$ & $-1.36( \pm 0.15)^{* * *}$ \\
\hline \multicolumn{5}{|c|}{ Other Autonomic Measures } \\
\hline $\begin{array}{c}\text { HR } \\
\text { (beats per minute) }\end{array}$ & $73.93( \pm 0.22)$ & $-1.63( \pm 0.16)^{* * *}$ & $-2.94( \pm 0.32)^{* * *}$ & $-4.40( \pm 0.34)^{* * *}$ \\
\hline HRV: Total Power (TP) & $761.8( \pm 19.05)$ & $+225.7( \pm 39.7)^{*}$ & $+436.1( \pm 64.6)^{* *}$ & $+206.6( \pm 49.6)$ \\
\hline HRV: High Frequency & $41.02( \pm 1.14)$ & $+18.4( \pm 2.7)^{*}$ & $+12.9( \pm 3.6)^{*}$ & $+5.2( \pm 2.7)$ \\
\hline Skin Temp (Centigrade) & $33.6( \pm 0.004)$ & $+1.18( \pm 0.01)^{* * *}$ & $+1.95( \pm 0.046)^{* * *}$ & $+2.28( \pm 0.02)^{* * *}$ \\
\hline \multicolumn{5}{|c|}{$\begin{array}{l}\text { Psycho-emotional state: Visual analog scales with numeric anchors: } \\
\qquad \begin{array}{l}0=\text { not; } 10 \text { = very (relaxed, stressed, peaceful) } \\
\text { ( } \pm \text { Standard Deviation) }\end{array}\end{array}$} \\
\hline Relaxed & $3.8( \pm 2.4)$ & \multicolumn{3}{|c|}{ Post NVCC: $8.8( \pm 1.2) *$} \\
\hline Stressed & $5.5( \pm 3.2)$ & \multicolumn{3}{|c|}{ Post NVCC: $2.2( \pm 1.7)^{*}$} \\
\hline Peaceful & $3.8( \pm 0.8)$ & \multicolumn{3}{|c|}{ Post NVCC: $9.0( \pm 0.9)^{* *}$} \\
\hline
\end{tabular}

Non-tactile NVCC - the practitioner practiced loving-kindness meditation while pretending to read a book

Tactile NVCC - the practitioner practiced loving-kindness meditation while touching the subject on the hands, arms, shoulders, knees, and hips "to test the effects on the autonomic nervous system"

* $\mathrm{P}<0.05$; ${ }^{* *} \mathrm{P}<0.01$; ${ }^{* *} \mathrm{P}<0.0001$

correlations between practitioner and subject RR during rest, tactile LKM, or post-intervention rest periods.

\section{Discussion}

Although compassion is a cornerstone of clinical care, there is a gap in research exploring the feasibility of measuring its direct psychophysiologic impact on subjects blind to the practitioner's intention. This preliminary study demonstrates that it is feasible to conduct blinded studies of the interpersonal effects of one form of NVCC, lovingkindness meditation (LKM) and provides preliminary evidence of significant psychophysiologic effects: increased relaxation, peacefulness, and heart rate variability, and decreased stress and respiratory rate.

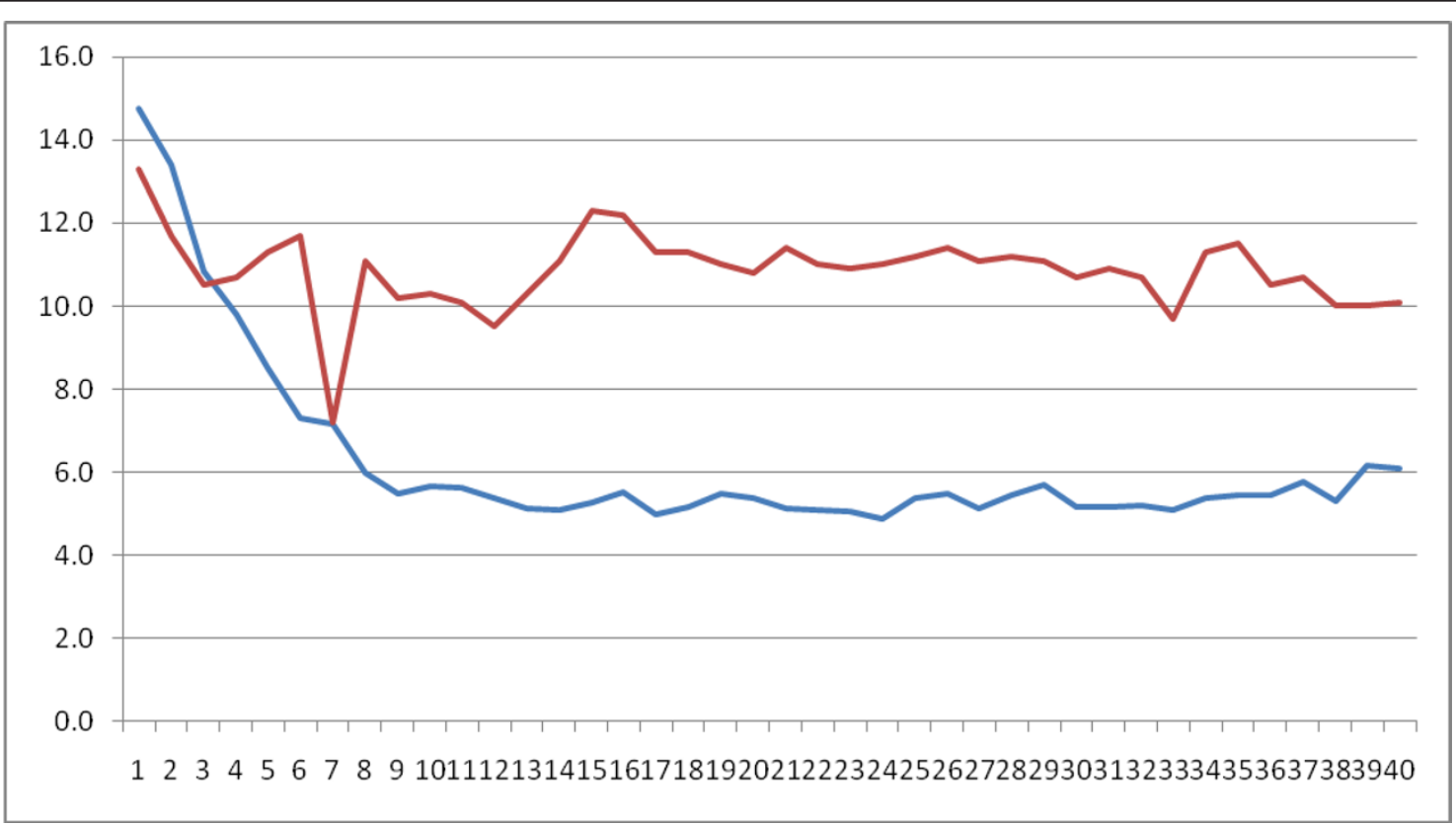

Figure 2 Average RR for Practitioner (blue) and Subjects (red) during Non-tactile NVCC over 10 minute intervention (40 15 second averages). Correlation, $r=0.55, P<0.001$. 
The practitioner's decrease in RR during LKM practice in this study is consistent with earlier studies showing significant decreases in RR with meditation [34,49,50]. Furthermore, these data suggest that in addition to having beneficial psychological and physiologic effects for practitioners [19,27,31,51-53], practicing compassion can also have physiologic and psychological effects on others, even when they are blind to the intervention.

Modern cultures place a premium on verbal communication. Thus, it is challenging to design experimental intervention strategies in which subject and practitioner are silently together over 40 minutes without arousing discomfort. We tested two strategies for blinding subjects to the intervention (reading and light touch) because each has pros and cons and may be better suited for clinical studies in different settings (e.g., psychotherapy vs. massage therapy). Practitioner "reading" is a useful blinding strategy because it is a common activity and generally results in a comfortable silence when two people are reading together; however, it is possible that subjects may be so absorbed in reading that they pay little attention to the practitioner's nonverbal cues, limiting their effects. It may also be challenging for less experienced practitioners to keep eyes open and focused on a page, turning pages from time to time while engaged in LKM, but it is feasible with practice. The light touch strategy allows the subject closer, undistracted observation of the practitioner, but may be uncomfortable outside of an established clinical context or relationship. The suggestion that the purpose of touch is to elicit autonomic activity is different from the suggestion that the purpose of touch is to comfort or heal, and suggestions themselves may have potent psychophysiologic effects $[6,54]$. These data suggest that both non-tactile and tactile strategies are feasible for blinding subjects to LKM; future clinical research can choose the strategy best suited for their study, e.g., nontactile "reading" for a study of the effects of NVCC during psychotherapy or educational interventions vs. tactile "touch eliciting effects on autonomic function" for studies of the effects of NVCC during massage or bodywork.

What conceptual model or theory might explain the expected benefits of NVCC? The theory of mirror neurons guided our study. Mirror neurons in the central nervous system (CNS) fire when an animal (or human) acts and when it simply observes another take that same action. These neurons unconsciously mirror other's behavior. Mirror neurons also fire in response to observed emotions [55-58]. Thus, individuals who are calm, e.g., who have a calm facial expression and slower, deeper respiratory rate (RR), may, via mirror neurons, trigger a sense of calm and perhaps a slower $R R$ in another person $[57,59-63]$. This study focused on mirrored RR because it is objective and easily measured. Our data are consistent with mirror neuron system (MNS) theory and studies showing that non-verbal communication of emotion and intention occur through the MNS outside of conscious awareness because our subjects showed psychophysiologic changes in the expected direction even though they were blind to the actual intervention $[57,61,64,65]$.

\section{Limitations}

Because this study was focused primarily on feasibility, it had a small convenience sample of healthy women in a fixed sequence design. Given the small sample size and low statistical power, we were surprised to find statistically significant effects on both self-reported psychological outcomes and objective physiologic measures. Although these results are intriguing, future studies should include a larger number of more diverse subjects in a randomized intervention order. Because empathy has been linked to MNS responses [57,59,61,64], future studies should also test whether subjects with varying degrees of empathy have varying autonomic and psycho-emotional effects with NVCC.

This study explored only RR signals although NVCC may include changes in facial expression, operating through different MNS pathways. Future studies may focus on facial expressions as cues for NVCC [66-69]. For such studies, video recordings of the practitioner and subject would be desirable. Furthermore, only one type of meditation was tested in this study. Some research suggests that different types of meditation have different physiologic impact on practitioners which may be translated into different nonverbal cues $[14,19,26,53,70,71]$. Future studies may compare the effects of lovingkindness meditation with other types of meditation practice.

The "dose" of optimal exposure to NVCC is unknown. This study used two 10 minute 'doses' of exposure to LKM, and although we noted an onset of effect on RR within that time, future studies should compare the impact of different durations LKM intervention.

The timing and duration of effects are unknown. We asked subjects to rate stress, relaxation, and peacefulness after both LKM interventions (20 minutes) and the postintervention rest period (10 minutes) with simple VAS scales rather than standardized psychological assessment tools. Since RR tended to return to baseline levels by the end of the post-intervention period, it may be preferable to ask subjects to complete self-report measures immediately after each intervention and to use standardized measures. If more than one type of LKM is provided, subjects should receive them in random order to minimize sequence effects, and there should be separate measurements and a "wash out" period between 
interventions to identify the unique effect of each intervention.

This study used an experienced LKM practitioner, and it is unclear whether the same effects would be found with practitioners who had brief training or little experience. Most studies comparing long-term with novice meditation practitioners have noted differences $[32,33,72,73]$. Clinically, it would be useful to know, for example could parents of anxious, hospitalized children be trained to practice LKM for and with their child, reducing the child's anxiety and stress? Could loved ones of palliative care patients be trained to extend LKM, and what impact would this have on patients' well-being, clinical outcomes, and satisfaction with care? How much LKM practice is sufficient to have a sustained and meaningful impact on others?

This study intentionally omitted any positive suggestion about the impact of NVCC on subjects. It is of clinical importance to understand how the benefits observed here with blind intervention could be augmented by positive suggestions.

For this study, the intervention used sham activities (reading and light touch), but did not require the practitioner to actually engage in another productive activity (e.g., checking a pulse, taking a history) during LKM. It would be worthwhile to determine the feasibility and impact of simultaneously engaging in LKM and another meaningful clinical activity. It would also be worthwhile to understand the effects of clinicians engaging in LKM prior to or between clinical activities on patients' sense of well-being and autonomic activity.

Temperature increases were noted throughout all four study periods, which could be consistent with relaxation or simply with the device equilibrating from room temperature to body temperature over time [74,75]. Future studies should use a control intervention or longer warm up period to ensure the device has reached a stable temperature before starting data collection.

Although the hypothesized mechanism for the effects of NVC observed in this study is the mirror neuron system, this study did not directly measure CNS activity, but focused instead on feasibility, self-report, and autonomic measures. Now that feasibility has been established and the data suggest psychophysiologic effects, it would be worthwhile to further test the mirror neuron theory of NVCC through imaging studies.

\section{Conclusion}

It is feasible to study the interpersonal effects of nonverbal compassionate communication on the autonomic nervous system and psycho-emotional state while maintaining subject blinding to the intervention using strategies appropriate for clinical situations including either tactile (e.g., massage) or non-tactile (e.g., psychotherapy) interactions. Furthermore, despite the small sample size in this preliminary study, the intervention (lovingkindness meditation with an experienced practitioner) was associated with significant changes in subjects' ANS as well as significant increases in relaxation and peacefulness even though subjects remained blind to the nature of the intervention. Future projects evaluating the impact of clinician or parent training can build on this work to explore the underlying mechanism and the clinical consequences of the interpersonal effects of communicating compassion.

\section{Abbreviations}

ANS: autonomic nervous system; CNS: central nervous system; HF: high frequency, a measure of heart rate variability from the power spectral calculation of HRV, often associated with vagal tone; higher values are associated with relaxation; $\mathbf{H R}$ : heart rate, measured in beats per minutes; HRV: heart rate variability; the variability in the interbeat interval; IBI: interbeat interval; LKM: lovingkindness meditation; LF: low frequency, a measure of heart rate variability from the power spectral calculation of HRV; NVC: non-verbal communication; NVCC: non-verbal communication of compassion; RR: respiratory rate, measured in breaths per minute; SDNN: standard deviation of the interbeat interval; often used as a proxy for HRV with higher values reflecting greater well-being; Temp: peripheral skin temperature; TP: Total Power, an overall measure of heart rate variability from the power spectral calculation of HRV; often used as a proxy for HRV with higher values reflecting greater well-being; VLF: Very low frequency, a measure of heart rate variability from the power spectral calculation of HRV.

\section{Acknowledgements}

We are grateful to Dr. Tim Houle who lent the BioCom equipment for this study and trained us in its use; Ralph D'Agostino, PhD who did the preliminary data analysis; Craig Hamilton, PhD who did preliminary HRV analysis; Rollin McCraty, PhD who helped us interpret HRV data; and Erica Rosenberger who helped with pre-study strategy development. We are also grateful to Drs. Kathy Poehling and Sharon Castellino in the Department of Pediatrics for their critical feedback on earlier drafts of the paper.

\section{Author details}

${ }^{1}$ Social Science and Health Policy, Pediatrics, Center for Integrative Medicine, and Hypertension and Vascular Research Center; Wake Forest University School of Medicine; Winston-Salem, NC, USA. ${ }^{2}$ Hypertension and Vascular Research Center, Center for Integrative Medicine, Department of Obstetrics and Gynecology; Wake Forest University School of Medicine; Winston-Salem, NC, USA.

\section{Authors' contributions}

KJK conceived of the project, developed the protocol, recruited subjects and practitioner, supervised the study, downloaded data, and analyzed the VAS, $\mathrm{RR}, \mathrm{HR}$, and Temperature data. Dr. Kemper wrote the drafts of the manuscript and revised them with input from Dr. Shaltout. HAS analyzed the HRV data, double-checked the other data analyses, wrote the HRV sections of the methods and results, and participated in revising and clarifying the paper.

Both authors read and approved the final manuscript.

Declaration of Competing interests

The authors declare that they have no competing interests.

Received: 8 June 2011 Accepted: 20 December 2011

Published: 20 December 2011

\section{References}

1. Lane RD, Waldstein SR, Chesney MA, Jennings JR, Lovallo WR, Kozel PJ, Rose RM, Drossman DA, Schneiderman N, Thayer JF, Cameron OG: The rebirth of neuroscience in psychosomatic medicine, Part I: historical 
context, methods, and relevant basic science. Psychosom Med 2009, 71:117-134.

2. $\quad$ Ong LM, de Haes JC, Hoos AM, Lammes FB: Doctor-patient communication: a review of the literature. Soc Sci Med 1995, 40:903-918

3. Richmond VP, McCroskey JC, Hickson ML: Nonverbal Behavior in Interpersonal Relations. Allyn and Bacon, 72001.

4. Cevasco AM: Effects of the therapist's nonverbal behavior on participation and affect of individuals with Alzheimer's disease during group music therapy sessions. J Music Ther 2010, 47:282-299.

5. Street RL, Makoul G, Arora NK, Epstein RM: How does communication heal? Pathways linking clinician-patient communication to health outcomes. Patient Educ Couns 2009, 74:295-301.

6. Campenni CE, Crawley EJ, Meier ME: Role of suggestion in odor-induced mood change. Psychol Rep 2004, 94:1127-1136.

7. Goffaux P, Redmond WJ, Rainville P, Marchand S: Descending analgesiawhen the spine echoes what the brain expects. Pain 2007, 130:137-143.

8. Kong J, Kaptchuk TJ, Polich G, Kirsch I, Vangel M, Zyloney C, Rosen B, Gollub RL: An fMRI study on the interaction and dissociation between expectation of pain relief and acupuncture treatment. Neuroimage 2009, 47:1066-1076.

9. Kong J, Kaptchuk TJ, Polich G, Kirsch I, Vangel M, Zyloney C, Rosen B, Gollub R: Expectancy and treatment interactions: a dissociation between acupuncture analgesia and expectancy evoked placebo analgesia. Neuroimage 2009, 45:940-949.

10. Kong J, Gollub RL, Rosman IS, Webb JM, Vangel MG, Kirsch I, Kaptchuk TJ: Brain activity associated with expectancy-enhanced placebo analgesia as measured by functional magnetic resonance imaging. J Neurosci 2006, 26:381-388.

11. Moerman DE, Jonas WB: Toward a research agenda on placebo. Adv Mind Body Med 2000, 16:33-46.

12. Neumann M, Edelhauser F, Kreps GL, Scheffer C, Lutz G, Tauschel D, Visser A: Can patient-provider interaction increase the effectiveness of medical treatment or even substitute it?-an exploration on why and how to study the specific effect of the provider. Patient Educ Couns 2010, 80:307-314.

13. Moerman D: Doctors and patients: the role of clinicians in the placebo effect. Adv Mind Body Med 2003, 19:14-22.

14. Sibinga EM, Kemper $\mathrm{KJ}$ : Complementary, holistic, and integrative medicine: meditation practices for pediatric health. Pediatr Rev 2010, 31 e91-e103.

15. Baron Short E, Kose S, Mu Q, Borckardt J, Newberg A, George MS, Kozel FA: Regional Brain Activation During Meditation Shows Time and Practice Effects: An Exploratory FMRI Study. Evid Based Complement Alternat Med 2007.

16. Holzel BK, Ott U, Gard T, Hempel H, Weygandt M, Morgen K, Vaitl D: Investigation of mindfulness meditation practitioners with voxel-based morphometry. Soc Cogn Affect Neurosci 2008, 3:55-61.

17. Luders E, Toga AW, Lepore N, Gaser C: The underlying anatomical correlates of long-term meditation: larger hippocampal and frontal volumes of gray matter. Neuroimage 2009, 45:672-678.

18. Engstrom M, Pihlsgard J, Lundberg P, Soderfeldt B: Functional magnetic resonance imaging of hippocampal activation during silent mantra meditation. J Altern Complement Med 2010, 16:1253-1258.

19. Engstrom M, Soderfeldt B: Brain activation during compassion meditation: a case study. J Altern Complement Med 2010, 16:597-599.

20. Kemper KJ, Fletcher NB, Hamilton CA, McLean TW: Impact of healing touch on pediatric oncology outpatients: pilot study. J Soc Integr Oncol 2009, 7:12-18.

21. Kemper KJ, Hamilton C, Atkinson M: Heart Rate Variability: Impact of Differences in Outlier Identification and Management Strategies on Common Measures in Three Clinical Populations. Pediatr Res 2007.

22. Kemper KJ, Hamilton CA, McLean TW, Lovato J: Impact of music on pediatric oncology outpatients. Pediatr Res 2008, 64:105-109.

23. Kemper KWCR, Yard B, Cohen DG, McLean T, Atkinson M: Heart rate variability in pediatric patients with leukemia: a brief report. J Cancer Int Med 2004, 2:137-143.

24. Tang R, Tegeler C, Larrimore D, Cowgill S, Kemper KJ: Improving the WellBeing of Nursing Leaders Through Healing Touch Training. J Altern Complement Med 2010, 16:837-841.

25. Travis F: Autonomic and EEG patterns distinguish transcending from other experiences during Transcendental Meditation practice. Int J Psychophysiol 2001, 42:1-9.
26. Lutz A, Brefczynski-Lewis J, Johnstone T, Davidson RJ: Regulation of the neural circuitry of emotion by compassion meditation: effects of meditative expertise. PLoS One 2008, 3:e1897.

27. Hutcherson CA, Seppala EM, Gross JJ: Loving-kindness meditation increases social connectedness. Emotion 2008, 8:720-724.

28. Barnhofer T, Chittka T, Nightingale H, Visser C, Crane C: State Effects of Two Forms of Meditation on Prefrontal EEG Asymmetry in Previously Depressed Individuals. Mindfulness (N Y) 2010, 1:21-27.

29. Carson JW, Keefe FJ, Lynch TR, Carson KM, Goli V, Fras AM, Thorp SR: Loving-kindness meditation for chronic low back pain: results from a pilot trial. J Holist Nurs 2005, 23:287-304.

30. Fredrickson BL, Cohn MA, Coffey KA, Pek J, Finkel SM: Open hearts build lives: positive emotions, induced through loving-kindness meditation, build consequential personal resources. J Pers Soc Psychol 2008, 95:1045-1062.

31. Feldman G, Greeson J, Senville J: Differential effects of mindful breathing, progressive muscle relaxation, and loving-kindness meditation on decentering and negative reactions to repetitive thoughts. Behav Res Ther 2010, 48:1002-1011.

32. Lutz A, Greischar LL, Perlman DM, Davidson RJ: BOLD signal in insula is differentially related to cardiac function during compassion meditation in experts vs. novices. Neuroimage 2009, 47:1038-1046.

33. Tloczynski J, Santucci A, Astor-Stetson E: Perception of visual illusions by novice and longer-term meditators. Percept Mot Skills 2000, 91:1021-1026

34. Morse DR, Martin JS, Furst ML, Dubin LL: A physiological and subjective evaluation of meditation, hypnosis, and relaxation. Psychosom Med 1977, 39:304-324.

35. Ditto B, Eclache M, Goldman N: Short-term autonomic and cardiovascular effects of mindfulness body scan meditation. Ann Behav Med 2006, 32:227-234.

36. Peng CK, Henry IC, Mietus JE, Hausdorff JM, Khalsa G, Benson $\mathrm{H}_{\text {, }}$ Goldberger AL: Heart rate dynamics during three forms of meditation. Int J Cardiol 2004, 95:19-27.

37. Peng CK, Mietus JE, Liu Y, Khalsa G, Douglas PS, Benson H, Goldberger AL: Exaggerated heart rate oscillations during two meditation techniques. Int J Cardiol 1999, 70:101-107.

38. Peressutti C, Martin-Gonzalez JM, J MG-M, Mesa D: Heart rate dynamics in different levels of Zen meditation. Int J Cardiol 2010, 145:142-146.

39. Telles S, Nagarathna R, Nagendra HR: Autonomic changes while mentally repeating two syllables-one meaningful and the other neutral. Indian $J$ Physiol Pharmacol 1998, 42:57-63.

40. Wu SD, Lo PC: Cardiorespiratory phase synchronization during norma rest and inward-attention meditation. Int J Cardiol 2010, 141:325-328.

41. Bartoli A, Bystrzycka E, Guz A, Jain SK, Noble MI, Trenchard D: Studies of the pulmonary vagal control of central respiratory rhythm in the absence of breathing movements. J Physiol 1973, 230:449-465.

42. LaFramboise WA, Woodrum DE, Guthrie RD: Influence of vagal activity on the neonatal ventilatory response to hypoxemia. Pediatr Res 1985, 19:903-907.

43. Gotoh S, Sun G, Kagawa M, Matsui T: A novel stress monitoring method through stress-induced respiratory alterations: non-contact measurement of respiratory $\mathrm{V}(\mathrm{T}) / \mathrm{T}(\mathrm{I})$ alterations induced by stressful sound using a $10 \mathrm{GHz}$ microwave radar. Journal of medical engineering \& technology 2011.

44. Costanzo LS: BRS Physiology. Philadelphia: Lippincott, Williams, and Wilkins, 52010.

45. Stein PK, Bosner MS, Kleiger RE, Conger BM: Heart rate variability: a measure of cardiac autonomic tone. Am Heart J 1994, 127:1376-1381.

46. Heart rate variability: standards of measurement, physiological interpretation and clinical use. Task Force of the European Society of Cardiology and the North American Society of Pacing and Electrophysiology. Circulation 1996, 93:1043-1065.

47. Sgoifo A, de Boer SF, Westenbroek C, Maes FW, Beldhuis H, Suzuki T, Koolhaas JM: Incidence of arrhythmias and heart rate variability in wildtype rats exposed to social stress. Am J Physiol 1997, 273:H1754-1760.

48. Laitinen T, Hartikainen J, Niskanen L, Geelen G, Lansimies E: Sympathovagal balance is major determinant of short-term blood pressure variability in healthy subjects. Am J Physiol 1999, 276:H1245-1252.

49. Travis F, Olson T, Egenes T, Gupta HK: Physiological patterns during practice of the Transcendental Meditation technique compared with 
patterns while reading Sanskrit and a modern language. Int J Neurosci 2001, 109:71-80.

50. Wu SD, Lo PC: Inward-attention meditation increases parasympathetic activity: a study based on heart rate variability. Biomed Res 2008, 29:245-250.

51. Sibinga EM, Kemper KJ: Complementary, holistic, and integrative medicine: meditation practices for pediatric health. Pediatr Rev 2010, 31 e91-103.

52. Yu X, Fumoto M, Nakatani $Y$, Sekiyama T, Kikuchi H, Seki Y, Sato-Suzuki I, Arita H: Activation of the anterior prefrontal cortex and serotonergic system is associated with improvements in mood and EEG changes induced by Zen meditation practice in novices. Int J Psychophysiol 2011.

53. Pace TW, Negi LT, Adame DD, Cole SP, Sivilli TI, Brown TD, Issa MJ, Raison CL: Effect of compassion meditation on neuroendocrine, innate immune and behavioral responses to psychosocial stress. Psychoneuroendocrinology 2009, 34:87-98.

54. Benedetti F, Lanotte M, Lopiano L, Colloca L: When words are painful: unraveling the mechanisms of the nocebo effect. Neuroscience 2007, 147:260-271

55. Critchley HD: Psychophysiology of neural, cognitive and affective integration: fMRI and autonomic indicants. Int I Psychophysiol 2009, 73:88-94.

56. de Vignemont F, Singer T: The empathic brain: how, when and why? Trends Cogn Sci 2006, 10:435-441.

57. Nummenmaa L, Hirvonen J, Parkkola R, Hietanen JK: Is emotional contagion special? An fMRI study on neural systems for affective and cognitive empathy. Neuroimage 2008, 43:571-580.

58. Parkinson B, Simons G: Affecting others: social appraisal and emotion contagion in everyday decision making. Pers Soc Psychol Bull 2009, 35:1071-1084.

59. Cattaneo L, Rizzolatti G: The mirror neuron system. Arch Neurol 2009, 66:557-560.

60. Bastiaansen JA, Thioux M, Keysers $C$ : Evidence for mirror systems in emotions. Philos Trans R Soc Lond B Biol Sci 2009, 364:2391-2404

61. Leslie KR, Johnson-Frey SH, Grafton ST: Functional imaging of face and hand imitation: towards a motor theory of empathy. Neuroimage 2004, 21:601-607.

62. Singer T, Seymour B, O'Doherty J, Kaube H, Dolan RJ, Frith CD: Empathy for pain involves the affective but not sensory components of pain. Science 2004, 303:1157-1162

63. Preston SD, de Waal FB: Empathy: Its ultimate and proximate bases. Behav Brain Sci 2002, 25:1-20, discussion 20-71.

64. Harris JC: Social neuroscience, empathy, brain integration, and neurodevelopmental disorders. Physiol Behav 2003, 79:525-531.

65. Le Bel RM, Pineda JA, Sharma A: Motor-auditory-visual integration: The role of the human mirror neuron system in communication and communication disorders. J Commun Disord 2009, 42:299-304.

66. Yang TT, Simmons AN, Matthews SC, Tapert SF, Bischoff-Grethe A, Frank GK, Arce E, Paulus MP: Increased amygdala activation is related to heart rate during emotion processing in adolescent subjects. Neurosci Lett 2007, 428:109-114.

67. Sauter DA, Eisner F, Ekman P, Scott SK: Cross-cultural recognition of basic emotions through nonverbal emotional vocalizations. Proc Natl Acad Sci USA 2010, 107:2408-2412

68. Baird AD, Scheffer IE, Wilson SJ: Mirror neuron system involvement in empathy: A critical look at the evidence. Soc Neurosci 2011, 1-9.

69. Hooker Cl, Verosky SC, Germine LT, Knight RT, D'Esposito M: Neural activity during social signal perception correlates with self-reported empathy. Brain Res 2010, 1308:100-113.

70. Travis F, Shear J: Focused attention, open monitoring and automatic selftranscending: Categories to organize meditations from Vedic, Buddhist and Chinese traditions. Conscious Cogn 2010, 19:1110-1118.

71. Bernardi L, Sleight P, Bandinelli G, Cencetti S, Fattorini L, Wdowczyc-Szulc J, Lagi A: Effect of rosary prayer and yoga mantras on autonomic cardiovascular rhythms: comparative study. Bmj 2001, 323:1446-1449.

72. Brefczynski-Lewis JA, Lutz A, Schaefer HS, Levinson DB, Davidson RJ: Neural correlates of attentional expertise in long-term meditation practitioners. Proc Natl Acad Sci USA 2007, 104:11483-11488.

73. Kaul P, Passafiume J, Sargent CR, O'Hara BF: Meditation acutely improves psychomotor vigilance, and may decrease sleep need. Behav Brain Funct 2010, 6:47.
74. Wenck LS, Leu PW, D'Amato RC: Evaluating the efficacy of a biofeedback intervention to reduce children's anxiety. J Clin Psychol 1996, 52:469-473.

75. Astin JA: Mind-body therapies for the management of pain. Clin J Pain 2004, 20:27-32.

\section{Pre-publication history}

The pre-publication history for this paper can be accessed here: http://www.biomedcentral.com/1472-6882/11/132/prepub

doi:10.1186/1472-6882-11-132

Cite this article as: Kemper and Shaltout: Non-verbal communication of compassion: measuring psychophysiologic effects. BMC Complementary and Alternative Medicine 2011 11:132.

\section{Submit your next manuscript to BioMed Central and take full advantage of:}

- Convenient online submission

- Thorough peer review

- No space constraints or color figure charges

- Immediate publication on acceptance

- Inclusion in PubMed, CAS, Scopus and Google Scholar

- Research which is freely available for redistribution

Submit your manuscript at www.biomedcentral.com/submit
Biomed Central 